\title{
AINDA UMA VEZ, VIRTUDE MORAL E VIRTUDE POLÍTICA: AS RUPTURAS MAQUIAVELIANAS
}

Once again, moral virtue and political virtue: Machiavellian ruptures

Sérgio Cardoso *

Resumo: No presente artigo, começamos por rememorar alguns marcos fundamentais das considerações da Antiguidade clássica sobre as relações entre virtude moral e virtude política - Aristóteles, o estoicismo moral ciceroniano -, para caminhar na direção da noção humanista de 'virtude cívica' e, ainda uma vez, desta ao conceito de virtù em Maquiavel. Procuramos, então, reconsiderar interpretações contemporâneas - Quentin Skinner, James Hankins - que entendem manter o vínculo ético desta virtù em vista de seu apego aos fins tradicionais da virtude política, a utilidade pública, o bem comum, para, enfim, mostrar que o tema central da obra do florentino - o da divisão civil entre grandes e povo, constitutiva da ordem política - incide diretamente sobre o conceito em causa e leva a ética (pública e privada) a filtrar-se na lógica da construção da vida comum entre os homens.

Palavras chave: Virtude moral. Virtude política. Maquiavel. Conflito civil.

Abstract: We will first begin this paper by recalling some key landmarks of classical antiquity concerning the relation between moral virtue and political virtue, Aristotle and Ciceronian moral stoicism. We will then move forward into the humanistic notion of "civic virtue" and, thenceforth, into Machiavelli's concept of virtù. Our intention, therefore, is to reconsider the contemporary interpretations of Quentin Skinner and James Hankins that have both aimed to maintain the ethical bond of this virtù, considering its attachment to the traditional goals of

* Professor Associado do Departamento de Filosofia da Universidade de São Paulo - FFLCH-USP. Artigo recebido em 16/11/2018 e aprovado para a publicação em 21/11/2018. 
political virtue, public utility and the common good. Finally, we will show that the major theme in the Florentine's work, that is, the civic division between the 'potenti' and the people, which is constitutive of political order, directly affects the concept at stake here, and leads ethics, both public and private, to refine itself in the making of common life among men.

Key-words: Moral Virtue. Political Virtue. Machiavelli. Civil Conflict.

$\mathrm{V}$ irtude moral e virtude política, Aristóteles as distingue. Ainda que a questão seja controversa na exegese de seus Políticos. No livro III, 4, propõe-se diretamente a examinar esse ponto: "se a virtude do homem bom e do bom cidadão são a mesma ou são diversas" ${ }^{\prime 1}$. E, como de hábito, o filósofo traz aí uma comparação esclarecedora. Num grupo de marinheiros, dadas as suas diferentes funções, há, para cada um, uma excelência própria: ser bom piloto, bom remador e assim por diante. Há, no entanto, uma excelência que se aplica a todos: "a navegação segura é um fim [um bem] comum; ela é, com efeito, o que deseja cada um dos marinheiros" ${ }^{\prime 2}$. Do mesmo modo, a virtude política desdobra-se em diferentes formas, observa ele; pois, trata-se de buscar o bem comum da cidade a partir de posições diversas e também, evidentemente, segundo os requisitos das diferentes constituições, não havendo, portanto, uma virtude única para um bom cidadão. Ela é sempre relativa às exigências de sua posição em cada regime.

Ora, tais cidadãos, como os marinheiros num barco, podem desempenhar bem suas funções (diversas e adequadas à constituição da sua cidade) sem ser homens de perfeita virtude (moral), já que "é impossível que exista uma cidade em que todos os cidadãos sejam homens bons; sendo, no entanto, necessário que cada um cumpra bem sua tarefa própria, como efeito de sua virtude própria" ${ }^{3}$. Isto mostra, segundo ele, que a virtude política, que é plural ${ }^{4}$, não coincide com a virtude (moral) do homem bom, que é única, a virtude perfeita. E há mais ainda: a própria virtude moral não se desdobra imediatamente em virtudes políticas, aquelas adequadas ao desempenho excelente de um cidadão em um determinado regime, já que não é o mesmo, por exemplo, ser 'bom cidadão' em uma democracia ou em uma aristocracia. Um homem moralmente bom pode não ser um bom cidadão em uma democracia, ainda que, por outro lado, nas aristocracias,

\footnotetext{
${ }^{1}$ ARISTÓTELES, Os Políticos, 1993, III, 4, 1276 b 18.

${ }^{2}$ Ibid., 1276 b 27.

${ }^{3}$ Ibid., 1276 b 38.

4 "Além do mais, visto que a cidade é formada por gente dissemelhante [...], é necessário que não haja uma excelência única para todos os cidadãos, como não há, entre os coreutas, para um corifeu e um assistente" (Ibid., 1277 a 5-10). A passagem (1288 a 37) que parece contradizer esta, como assinalaremos adiante, diz respeito a uma cidade que fosse perfeita (ou uma perfeita aristocracia).
} 
os traços do bom cidadão devam, evidentemente, coincidir com aqueles do homem bom: "só o governo dos melhores absolutamente segundo a virtude, e não de um homem bom em uma perspectiva particular, pode ser legitimamente chamado aristocracia. Com efeito, apenas aí o homem de bem e o bom cidadão são um só e mesmo absolutamente, enquanto nas outras [constituições], apenas são bons em relação à constituição que é a deles ", diz, no livro IV, $7^{5}$, o capítulo dedicado à natureza e às qualidades das aristocracias. Mas, já no livro III, 18, isto estava devidamente patenteado: "[...] a excelência de um homem bom é a mesma que aquela de um cidadão da cidade excelente" ${ }^{\prime \prime}$, aquela dos 'sonhos' de um nomotheta.

Porém, essa disjunção realista admitida por Aristóteles não é o padrão das relações entre excelência moral e excelência política, dos antigos até o "humanismo cívico" do Renascimento. Aqui o paradigma clássico é aquele estabelecido por Cícero, mormente, em seu catecismo moral Dos deveres, talvez o texto da antiguidade clássica que mais influente foi entre os humanistas. Nesse escrito, a última de suas obras (endereçada como uma herança ao filho e, através dele, aos jovens romanos dos extratos sociais superiores), Cícero entende fundar algo já intensamente presente em seus primeiros textos políticos - o De re publica, o De oratore, o De legibus, redigidos entre 55 e 51 a.C. -, seu combate ao alheamento das novas elites romanas em relação ao interesse público e a afirmação da exigência moral da participação na vida pública. Impõe-se o preceito da colocação do interesse comum à frente daqueles privados (alimentados, estes, pelos apelos da utilidade e do prazer) ou até mesmo do chamado à especulação filosófica, como em sua crítica aos epicuristas no proêmio do De republica. Como é sabido, no seu tratado Dos deveres, o filósofo assenta a dimensão e o alcance políticos do sistema da moralidade, estabelecendo a precedência dos deveres relativos à comunidade (officia ex communitate) sobre todos os outros e produzindo o argumento que, adiante, no Renascimento, virá alimentar o embate pela superioridade da 'vida ativa' sobre a 'contemplativa' e das virtudes cívicas sobre aquelas do indivíduo dedicado ao cultivo da própria excelência moral (sustentada quase sempre pelo esteio das disciplinas da oração e da contemplação) $)^{7}$. Nessa obra, como se sabe também, Cícero, sem contradição com sua profissão cética, assume a moralidade estoica como a mais aprovável, mantendo, portanto, a suspensão no que diz respeito aos fundamentos desta moralidade. Pois, ele adverte que não se apresenta nesse trabalho como um intérprete do

\footnotetext{
${ }^{5}$ Ibid., IV, 7, 1293 b 2-7.

${ }^{6}$ Ibid., III, 18, 1288 a 38.

${ }^{7}$ Para a presença do pensamento de Cícero entre os Renascentistas - sobretudo quanto ao Della Vita Civile de Matteo Palmieri e seu empenho em fundar, pela conexão entre a virtude cívica e os desígnios divinos, uma moralidade política no contexto dos valores cristãos -, conferir o ensaio de Helton Adverse: "Virtude moral e virtude política no Renascimento Italiano: o sonho de Dante no Vita Civile de Matteo Palmieri", in IDEM (org.), Filosofia política no Renascimento Italiano, 2013.
} 
estoicismo; vai a ele, nas suas palavras, "conforme nosso costume, tirando de suas fontes, segundo nosso tirocínio e arbítrio, aquilo que nos aprouver" ${ }^{\prime \prime}$. Observação necessária, visto que procede a várias críticas ao peri tou kathekontos, o catecismo moral de Panécio de Rodes, que toma como ponto de partida de sua exposição.

A principal destas críticas, sabemos, é aquela que assinala no manual do filósofo estoico (que disserta sobre o honesto, o útil, e sobre os aparentes conflitos entre o útil e o honesto) uma lacuna importante para o acabamento de seu sistema da moralidade: "com efeito, diz Cícero, não se costuma deliberar apenas sobre se alguma coisa é honesta ou desonesta, mas também acerca daquilo que é mais honesto entre dois propósitos honestos e, do mesmo modo, acerca do mais útil entre dois propósitos úteis" . Ora, é justamente por esta brecha aberta no sistema estoico que se insinua a decisiva afirmação da precedência dos officia relativos à comunidade, em relação, sobretudo, àqueles deveres voltados ao conhecimento. Tal proposição traz consigo a afirmação da proeminência da ação sobre a contemplação, que o racionalismo e o rigorismo estoicos (que tudo remetem à homologia, à conformidade com a natureza e à intenção moral do agente - o agir por dever e não em função dos alvos da ação) certamente encontram alguma dificuldade para assimilar. Pois, a virtude estoica, ao rebaixar o 'escopo', os bens visados pela ação, a meios para o exercício da virtude, tende a concentrar-se na intenção moral do agente e passa a visar como télos, tão somente a retidão moral da ação conforme à natureza. Assim, parece ofuscar a eficácia prática da ação e reforçar sua dimensão noética (conhecer o que a natureza quer para consentir consciente e racionalmente ao que ela impõe), fazendo o exercício da virtude tender a fixar-se no agente singular, tender a se personalizar e individualizar, afastar-se do horizonte da ação comum.

Ora, em Cícero, os princípios do estoicismo moral ganham uma certa inflexão: ele retoma a cada momento o mote de que a verdadeira virtude está no seu exercício e na prática da vida comum, concreta, do agente moral inscrito em uma comunidade e engajado em seus skopoi apropriados. Milton Valente, excelente leitor da ética ciceroniana, assinala esse movimento com grande acuidade: "importa pouco à Cícero pintar-nos o ideal de uma sabedoria abstrata. Seu propósito era outro: dar ao homem, cuja reflexão é com frequência impotente para ultrapassar a esfera da utilidade, uma linha de conduta inflexível e de valor absoluto - o sentido do bem comum"10. A moralidade passa, então, a ser definida não mais imediatamente pelo que a natureza "quer"; pois, esse télos vê-se mediado pelo que a vida social "requer" do sujeito moral, visto que a busca da utilidade comum,

\footnotetext{
${ }^{8}$ CÍCERO, De officiis, 1965, I, 6.

${ }^{9}$ Ibid., I, 10.

${ }^{10}$ VALENTE, M., A Ética Estóica em Cícero, 1984, p. 391.
} 
o bem de sua cidade, entre os propósitos honestos é o que a natureza dos homens, seres comunitários, mais quer.

Como se vê, Cícero, em um certo sentido, faz um caminho em direção inversa àquele de Aristóteles. Se este é levado a admitir que o bom cidadão pode não coincidir com o homem de excelência moral perfeita, dissociando, como vimos, em certa medida, a virtude moral e a virtude política, Cícero, por seu lado, faz da segunda, da virtude cívica, o próprio paradigma da excelência perfeita: a busca da utilidade comum figura, vimos, entre as coisas honestas, o mais honesto. De um lado, porque "a virtude reside inteiramente em seu exercício" ${ }^{\prime 11}$; de outro lado, porque seu alvo maior é a promoção do bem comum, o serviço da pátria - na expressão do filósofo, "a conservação da vida em comunidade", a primeira das inclinações naturais dos homens. E será exatamente este o ensino assumido, a seu modo, tanto pelos manuais do gênero "speculum principis", como também pelos pensadores do humanismo cívico: primazia da ação sobre a contemplação, maior dignidade da vida política; enfim, a vida ativa como forma de vida superior, a eminência da virtude cívica. $\mathrm{O}$ bom cidadão, dedicado à pátria, é o homem da virtude perfeita, merecedor da glória supraterrena, como ensina o "sonho de Cipião", no final do De re publica.

É verdade, como verifica Quentin Skinner, que, ao longo dos séculos XIV e XV, essa concepção ciceroniana da excelência moral vai ganhando uma face renovada, vai assumindo novos traços - sem abandonar, devemos observar, seu enquadramento clássico, bem como sua constante associação à forma de governo republicana, vista como aquela mais adequada para o desabrochar da virtude. Vem, em primeiro lugar, mostra-nos o historiador das ideias, por oposição ao conceito medieval de nobreza, a ideia de que esta não pode ser medida "pela antiguidade da linhagem ou pelo volume das riquezas, mas acima de tudo pela capacidade de desenvolver os próprios talentos, de atingir um senso adequado de espírito público e, assim, canalizar as energias para o serviço da comunidade"12. Acentuam-se, pois, as ideias de "esforço e mérito" e, logo, a projeção da virtude na força moral que sustenta a ação do cidadão no sentido de levar sua cidade à grandeza e à glória - uma força moral alimentada nas repúblicas pela emulação produzida na competição pelas honras públicas e pela glória $^{13}$. Na visão de Skinner, no entanto, o deslocamento fundamental está na acentuação do traço de vigor, força moral e de caráter, que leva o vir virtutis a vencer os obstáculos com que se defronta em sua ação pelo

11 CÍCERO, De re publica, 1994, I, 2: "não basta possuir virtude como se fosse uma arte qualquer, se ela não for usada".

12 SKINNER, Q., Fundações do pensamento político moderno, 1996, p. 102.

13 Pode-se observar que o empenho na busca das honras públicas e da glória não é, certamente, estranho à matriz ciceroniana e nem à associação que, posteriormente, se fará - em Patrizzi, sobretudo - desta virtude política com a formação nas disciplinas da retórica e da filosofia moral. 
bem público - um traço que tenderia a referir a virtude novamente ao desempenho do indivíduo moral, à sua "força criativa capaz de moldar o próprio destino e fazer o mundo social adequar-se a seus desejos" ${ }^{\prime \prime}$, trazendo para si e para a cidade honras públicas e glória.

Ora, segundo nosso historiador das ideias políticas, o pensamento de Maquiavel se inscreveria na linhagem direta dessas concepções humanistas. Também ele, diz, associa a virtude à capacidade de agir que visa à grandeza e à glória do agente e da cidade. Porém, o secretário florentino radicalizaria estas postulações herdadas do humanismo cívico, desembaraçando tais aspirações do ator político virtuoso das amarras morais e constitucionais. Tratar-se-ia aqui de fazer "o que for necessário" para conservar a cidade e sua liberdade e conquistar a glória, mais uma vez, a própria e a de sua pátria. O fim permaneceria, portanto, o mesmo que aquele dos humanistas cívicos, ainda que a medida da virtude do agente passe a ser "a necessidade". O fim, agora, segundo Maquiavel, imporia seus meios, fossem eles os que fossem: “donde é necessário - diz - querendo um príncipe se manter, aprender a poder ser não bom e usá-lo ou não o usar, consoante a necessidade"15. Estaria concluída desta maneira a ruptura com a tradição (estoico-cristã) e estabelecido o escândalo do maquiavelismo. A virtù (política) se sobreporia à virtute (moral) nas práticas da vida em comum.

Mas, que entendamos bem esta ruptura, diz Skinner: "vulgariza o pensamento de Maquiavel quem lhe cola a etiqueta de pregador do mal ${ }^{16}$. Ele está longe de querer tomar o mal por bem e é bem raro que diga que as virtudes tradicionais não devam ser consideradas admiráveis em si mesmas"17. É sabido que Maquiavel recusa a Agátocles, o tirano da Sicília, "que se conduziu como criminoso" ao longo de sua vida, o selo da virtù principesca, não obstante seu sucesso. Não se pode identificar a virtù ao vício ${ }^{18}$. Mas, é verdade também que a virtù, aqui, não exclui o vício: "a noção definitiva de quem é homem de virtù para Maquiavel e suas palavras finais de aconselhamento ao príncipe podem ser resumidas dizendo-se que ele o aconselha a que, mais do que tudo, trate de tornar-se um homem de 'disposição flexível', capaz de variar sua conduta do bem ao mal e do mal ao bem conforme lhe ditarem a Fortuna e as circunstâncias"19. Nem sempre se poderia agir segundo os padrões a que se aspira e que se admiram. A virtù assinalaria, portanto, essa disposição para a flexibilidade moral do ator político: aceitar o que a

\footnotetext{
${ }^{14}$ SKINNER, ibid., p. 115.

${ }^{15}$ MAQUIAVEL, O Príncipe, 2017, cap. XV, p. 183.

16 Trata-se, certamente, da leitura mais longeva e persistente da obra: ela promoveria o maquiavelismo. Esta compreensão ganha corpo no século XVI francês (o das guerras de religião), estende-se pela Inglaterra do século XVII e nos alcança, paradigmaticamente, com a interpretação de Leo Strauss, que vê em Maquiavel a ruptura do direito natural dos clássicos e a expressão de uma política demoníaca.

${ }_{17}$ SKINNER, ibid., p. 138.

${ }^{18}$ Cf. ibid., p. 159.

${ }^{19}$ Ibid.
} 
necessidade impõe, seja pela variação das circunstâncias, seja dos tempos. Assim, para nosso comentador, os fins da ação política para Maquiavel permaneceriam os mesmos da tradição da moral aristocrática e humanista ("mantenere lo stato", realizar grandes feitos, buscar honra e glória para si e para a cidade); mas, tais fins já não se mostrariam mais alcançáveis apenas pelas disposições convencionais da moralidade. Impõe-se, no nosso mundo turvo, acolher a violência e o mal... quando necessários.

James Hankins não discorda de Skinner; mas, na sua trilha, procura trazer outros balizamentos para o caminho maquiaveliano. Entende mostrar a natureza propriamente ética desta flexibilidade moral, desta dissociação entre os fins fixados pela tradição da moralidade (a utilidade comum, a conservação e o serviço da comunidade) e os meios, distanciados dos preceitos das virtudes convencionais. Assinala que o deslizamento se dá em uma camada mais profunda que aquela da superfície das relações políticas. A operação maquiaveliana supõe, mostra ele, tanto o afastamento do princípio metafísico-teológico (e 'eudaimonista') dos Antigos, quanto, mais especificamente, da convicção estoica sobre a inteira racionalidade da natureza, bem como a do agente moral que, como parte da natureza, busca conformar-se a ela racionalmente. Perde-se, enfim, em Maquiavel, a garantia metafísica para a correspondência entre o agir honesto racional - $\mathrm{o}$ do sábio - e a utilidade que resulta de sua ação (o que permitia a Cícero dizer "só é útil o que for honesto"); pois, é esse "ato de fé na racionalidade oculta do mundo", segundo a feliz formulação de Pierre Aubenque, que sustenta a preceptiva moral paradigmática do De officiis. Ora, sem tal garantia da realização necessária dos fins racionais da natureza (a que os preceitos morais buscam se conformar), o agente se descobre destituído da fiança da razão universal e, portanto, responsável pelos resultados de seus atos; pois, agora, diz o intérprete, "nem todo fim bom pode ser assegurado por bons meios e nem todo meio bom leva a um bom fim" ${ }^{20}$. Abrir-se-iam, portanto, aqui, "os dilemas da ética moderna" ${ }^{21}$.

Não haveria, portanto, em Maquiavel, um divórcio entre a política e a moralidade, mas o exercício de uma nova racionalidade ética, a de uma "ética consequencialista", que impõe ao ator político o cálculo relativo aos resultados de cada uma de suas ações, que exige dele a responsabilidade pelas consequências de seus atos, inscritos sempre em um quadro de circunstâncias contingentes. Contingentes, mas não imprevisíveis, observa Hankins, pois isto inviabilizaria a responsabilidade pelas ações. É necessário que o agente conte com uma razoável previsibilidade sobre os resultados de seus atos, uma exigência a que Maquiavel responderia com seu conceito (pessimista) de uma natureza humana razoavelmente uniforme no espaço

${ }^{20}$ HANKINS, J., "Humanism and the origins of modern political thought", in KRAYE, Jill (ed.), The Cambridge Companion to Renaissance Humanism, 1996, p. 136.

${ }^{21}$ HANKINS, ibid., p. 131. 
e no tempo, inteiramente movida pelos impulsos egoístas e pela rivalidade dos homens, mediados - e medidos - por cálculos racionais. Passaríamos, pois, da imprevisibilidade dos comportamentos humanos, dominados pelos apelos aleatórios das paixões (que a ética dos Antigos, justamente, pretende disciplinar através de sua preceptiva racional) à previsibilidade que se oferece ao cálculo, ainda que sempre limitado, da virtù do ator político, que aplica os postulados desta antropologia às circunstâncias de sua ação. A "ciência política" de Maquiavel coincidiria, assim, com esta "ética consequencialista': "o observador experimentado [da natureza humana], diz Hankins, estará apto a predizer o comportamento dos atores políticos e, então, a tomar decisões corretas, de modo a evitar consequências indesejáveis" ${ }^{22}$. Não haveria, enfim, divórcio entre política e moralidade, como pensam muitos leitores de Maquiavel ${ }^{23}$; pois, é esse "novo mundo ético que Maquiavel começa a explorar na segunda década do século $\mathrm{XVI}^{\prime 24}$, diz ele.

São muitas as dificuldades dessa interpretação. A primeira delas, a projeção de uma "natureza humana", universalmente inscrita nos indivíduos interesseiros e egoístas - a volta, pela porta dos fundos, de um naturalismo travestido de ciência (ou de hipótese científica) de embasamento da ordem política. Claude Lefort já nos adverte sobre esse equívoco em seu artigo "Machiavel, la dimension économique du politique" 25 , um dos textos mais esclarecedores de sua exegese da obra: "cederíamos à mesma ilusão da maioria dos intérpretes imaginando que a natureza do homem decide aquela de suas relações sociais. As considerações de Maquiavel sobre sua natureza só ganham a cada vez todo seu sentido nos limites de um argumento particular; e por esta razão, são frequentemente contraditórias. [...] O que importa a nosso autor não é portanto a natureza humana, tomada em si mesma, é a divisão de um desejo que somente se forma no estado social ou, mais precisamente, o estado político (lá onde há cidade): oprimir-não ser oprimido" 26 . Tema de difícil interpretação, portanto, este de uma "antropologia maquiaveliana", da qual ao menos se pode dizer que não se resolve sem a consideração da fratura política do social que constitui a marca fundamental da obra do filósofo.

Precisamos lembrar, em primeiro lugar, que esse tema dos "meios não bons" refere-se ao ator político dos novos principados e que não corresponde aos 'meios extraordinários' da ação popular nas repúblicas. Nestas, o povo recorre aos tumultos e violências, diz Maquiavel, para obter leis contra a opressão dos grandes quando falham ou inexistem canais institucionais, 'ordinários', para contê-los. A passagem é conhecida: “Os romanos tinham esse modo. Quando o povo queria obter uma lei, ou fazia uma das coisas

\footnotetext{
${ }^{22}$ Ibid., p. 137.

${ }^{23}$ Cf. ibid., p. 136.

${ }^{24}$ Ibid.

${ }^{25}$ LEFORT, Cl., Les formes de l'histoire, 1978.

${ }^{26}$ Ibid., p. 131.
} 
indicadas acima [tumultos e violências] ou se negava a arrolar seu nome para ir à guerra, de tal modo que para aplacá-lo era preciso satisfazê-lo em alguma coisa" ${ }^{27}$. Ora, o principe nuovo, ator político de virtù, aliado do povo, recorre aos expedientes "tidos por" viciosos ${ }^{28}$ no quadro de uma ordem constitucional dada, o Principado político ${ }^{29}$, e fundamentalmente contra os grandes, os poucos ("seus iguais" e, de algum modo, concorrentes), usando tais meios em vista do mantenere lo stato. Veja-se o capítulo XVII sobre a crueldade e a piedade, a formulação paradigmática relativa a estes procedimentos: "deve um príncipe não se preocupar com a fama de cruel para manter seus súditos unidos e fieis, visto que, com pouquíssimos exemplos, será mais piedoso do que aqueles que, por demasiada piedade, deixam prosseguir as desordens, de que nascem massacres e rapinas; porque estas costumam ofender uma coletividade (universalità) inteira, ao passo que as execuções que provêm do príncipe ofendem um particular" ${ }^{\prime \prime}$. E lembremos ainda outra passagem, esta do capítulo IX: "[...] não se pode satisfazer os grandes com honestidade e sem injúria para com os outros, mas o povo sim: porque a finalidade do povo é mais honesta que a dos grandes, querendo estes oprimir, e aquele não ser oprimido"31. O povo, o príncipe precisa tê-lo como amigo ${ }^{32}$ ou ao menos como não hostil. Não pode decepcioná-lo, parecer-lhe ser mal, egoísta, violento, caso em que ele lhe retira sua adesão e, com ela, o poder. Assim, o povo surge aqui como "mais honesto" e também como aquele que exige do príncipe uma imagem de moralidade ${ }^{33}$; não pode vê-lo como movido por interesses particulares - como um entre outros no jogo das ambições -; precisa crer que seja movido pelo que ele, povo, tem por virtude: a honestidade e a busca do interesse comum ${ }^{34}$.

${ }^{27}$ MAQUIAVEL, Tutte le opere, 1971, "Discorsi", I, 4, p. 23.

${ }^{28}$ Cf. IDEM, O Príncipe, 2017, cap. XV, p. 183.

${ }^{29}$ Este principado, tornado 'político' por sua aliança com o povo é, certamente, o objeto central do tratado de Maquiavel. Cabe insistir na lembrança do cap. IX: " [...] digo que se ascende ao principado ou com o apoio do povo, ou dos grandes. Porque em todas as cidades se encontram esses dois humores distintos: e disto nasce que o povo deseja não ser comandado nem oprimido pelos grandes e os grandes desejam comandar e oprimir o povo; e desses dois apetites distintos nasce na cidade um de três efeitos: ou principado, ou liberdade, ou licença. O principado é causado ou pelo povo ou pelos grandes, consoante seja uma ou outra dessas partes que tem a ocasião: porque os grandes, vendo que não podem resistir ao povo, começam a dirigir a reputação para um deles e fazem-no príncipe a fim de poderem, à sua sombra, saciar o apetite deles; o povo também, vendo que não pode resistir aos grandes, dirige a reputação para um só e o faz príncipe, para ser defendido pela sua autoridade" (ibid., p. 147, grifos nossos). ${ }^{30}$ Ibid., cap. XVII, p. 193, grifos nossos.

${ }^{31}$ Ibid., p. 147-9.

${ }^{32}$ Cf. Ibid., p. 149.

${ }^{33}$ Cf. ibid., cap. IX.

${ }^{34}$ Newton Bignotto, em excelente ensaio sobre as relações entre ética e política em Maquiavel, não deixa de lembrar que para o florentino "a política depende [sim] dos julgamentos morais, uma vez que os homens sempre avaliam seus governantes a partir de noções herdadas da tradição, embora eles não sejam capazes de discernir a verdade ou não das palavras do príncipe. [...] Falar, pois, do lugar das representações [as representações comuns do bem e 
A observarmos bem, portanto, o príncipe se equilibra entre, de um lado, a necessidade de enfrentar os grandes - atuais e virtuais opositores, os "lobos" - de onde a necessidade de "ser mau", e, de outro lado, aquela de obter a adesão dos 'muitos', do povo, que não pode vê-lo como um entre outros em competição pelo poder. Desse modo, não podendo "ser bom" ("... pois, é preciso ser raposa para conhecer as armadilhas e leão para assustar os lobos" ${ }^{\prime \prime 3}$ ) deverá aos olhos do povo, ao menos parecer "não mau", o que o obriga a limitar "suas maldades" em relação aos particulares, os grandes (seus adversários ou mesmo inimigos), a entrar no mal apenas quando necessário, sob pena de parecer (e ser) tirânico. Enfim, tomar o partido popular, o do universale, conter as ambições dos 'poucos' e, aos olhos dos muitos, parecer e ter, na medida do possível, as qualidades tidas por virtuosas: ser liberal, piedoso, fiel, humano, íntegro, religioso, e fugir da má fama dos vícios contrários ${ }^{36}$, também na medida do possível; e igualmente, "vencer e manter o estado"; pois, onde não há um juiz para o qual reclamar, olha-se o resultado ${ }^{37}$ : o vulgo "prende-se é com o que parece e ao desfecho das coisas; e no mundo não existe senão o vulgo, pois os poucos não têm aqui lugar quando os muitos têm onde se apoiar" 38 ; apoiar-se em um agente político de virtù, beneficiado pela fortuna, coroado pela glória.

Diante dessas relações intrincadas entre virtudes e vícios no domínio político (entre o que se dá como virtude ou por vício efetivos e o que parece virtude ou vício, revelando-se, entretanto, seus contrários ${ }^{39}$ ), dizer que, em Maquiavel, ética e política se separam - que há uma autonomização da política, ou ainda afirmar que sua política traduz uma 'ética consequencialista' - não nos parece satisfazer à nossa questão sobre suas relações. É certo que a ética de estofo estoico-cristão, a moralidade das prescrições racionalmente deduzidas de princípios, não tem mesmo mais lugar aqui, num mundo que perdeu sua necessidade (natural-racional), seus alicerces metafísicos, e não acedeu ainda à pretensão de uma ciência experimental apta a sustentar os cálculos racionais do agente político. Merleau-Ponty o atesta com fineza: "considerando esta história em que há tantos inesperados e reviravoltas, Maquiavel nada vê que a predestine a uma consonância final [...] Ele evoca a ideia de um acaso fundamental que a roubaria ao controle dos mais inteligentes e dos mais fortes" ${ }^{\prime 4}$. Deste

\footnotetext{
do mal] não implica em dizer que a ética não tem nenhum papel na política. Corresponde a mostrar que a ética, vivida como costume, é a janela através da qual percebemos as ações humanas" (BIGNOTTO, "As fronteiras da Ética: Maquiavel", in NOVAES, Adauto (org.), Ética, 1992, p. 117.

${ }^{35}$ MAQUIAVEL, O Príncipe, 2017, cap. XVII, p. 196.

${ }^{36}$ Cf. ibid., cap. XV, p. 183.

${ }^{37}$ Ibid., cap. XVIII, p. 201.

${ }^{38}$ Ibid., cap. XVIII, p. 201.

${ }^{39}$ Cf. ibid., cap. XV, p. 185.

${ }^{40}$ MERLEAU-PONTY, M., Signes, 1960, p. 375.
} 
modo, na ausência de uma diretriz racional, mergulhada nesse mundo de contingência radical e de embate de interesses e paixões é, na verdade, a ética que migra para o terreno da política, novamente elevada, então, a saber arquitetônico da razão prática (ainda que num quadro diverso do aristotélico). Não é, pois, a política que se mantém ética pela postulação de fins retos, pela busca do bem comum e da concórdia; mas, é toda a ética (pública e privada, é preciso dizer) que se deixa filtrar na lógica da política: as exigências do parecer (pois, não há transparência nas relações humanas), a necessidade de enfrentar a divisão social entre os grandes e o povo (movidos os primeiros pelo desejo de bens e poder, o outro pelo desejo de lei e de liberdade ${ }^{41}$ ) e a diferença do tempos - condições de realização de uma vida comum entre os homens.

"[...] Non partirci dal bene, ma sapere intrare nel male, necessitato" 42 . Merleau-Ponty, em sua extraordinária "Nota sobre Maquiavel", comenta mais uma vez com sua conhecida agudeza: "preceito de política que bem poderia ser também a regra de uma verdadeira moral"43. E continua: "a ideia de uma humanidade fortuita e que não tem causa ganha é o que dá valor absoluto à nossa virtude" ${ }^{44}$. Há, sem dúvida, distinções analíticas e semânticas entre virtù e virtute; porém, em Maquiavel "a verdadeira moral" é, certamente, política - como lembra Merleu-Ponty: "uma relação com homens e não com princípios".

\section{Referências Bibliográficas}

ARISTOTE. Les Politiques [Os Políticos]. Traduction, introduction, bibliographie, notes et index par Pierre Pellegrin. 2e édition. Paris: GF-Flammarion, 1993.

ADVERSE, Helton. "Virtude moral e virtude política no Renascimento Italiano: o sonho de Dante no Vita Civile de Matteo Palmieri", in ADVERSE, H. (org.). Filosofia política no Renascimento Italiano. São Paulo: Annablume, 2013.

BIGNOTTO, Newton. "As fronteiras da Ética: Maquiavel". In NOVAES, Adauto (org.). Ética. São Paulo: Cia. das Letras, 1992.

\footnotetext{
${ }^{41}$ Maquiavel além das passagens mais conhecidas sobre a divisão civil e a instituição e defesa das Leis referidas ao desejo popular de não opressão no Príncipe (cap. IX) e nos Discursos (L. I, 3 e 4), retoma estas considerações nas suas Histórias Florentinas desde o "Proêmio". A passagem mais lembrada é aquela que inicia o Livro III (MAQUIAVEL, Tutte le Opere, 1971, p. 690); porém, talvez, mais esclarecedora ainda seja aquela do Livro II, 12. Aí, ao assinalar um momento de apaziguamento dos conflitos entre gibelinos e guelfos, Maquiavel observa que, então, "apenas permaneciam acesos aqueles humores que costumam existir em toda cidade entre os poderosos (potenti) e o povo; porque querendo o povo viver sob leis e os poderosos querendo colocar-se acima delas, não é possível que se entendam" (Ibid., p. 666).

${ }^{42}$ IDEM, O Príncipe, cap. XVIII, p. 200; e também cap. XV, p. 182.

${ }^{43}$ MERLEAU-PONTY, M., ibid., p. 284.

${ }^{44}$ Ibid., p. 277.
} 
CICERON. Les Devoirs [De officiis]. Texte établi et traduit par M. Testard. Paris: Belles Lettres, 1965.

CÍCERO. Dos Deveres. Trad. Angélica Chiappetta, revisão de Gilson Cesar Cardoso de Souza. São Paulo: Martins Fontes, 1999.

CICERO. On the Republic [De re publica], On the Laws [De legibus]. Translated by Clinton W. Keyes. Cambridge, MA: Harvard University Press, 1994.

HANKINS, James, "Humanism and the origins of modern political thought", in KRAYE, Jill (ed.), The Cambridge Companion to Renaissance Humanism. Cambridge: Cambridge Univ. Press, 1996.

LEFORT, Claude. "Maquiavel, a dimensão econômica do político". In IDEM, As formas da história. São Paulo: Brasiliense, [1974?] . Les formes de l'Histoire. Paris: Gallimard, 1978.

MACHIAVELLI, Nicolò. Tutte le Opere. A cura di Mario Martelli. Firenzi: Sansoni, 1971.

MACHIAVEL. Oeuvres Complètes de Machiavel. Paris: Gallimard, 1952.

MAQUIAVEL. O Príncipe. Trad., intr. e notas de Diogo Pires Aurélio. São Paulo: Editora 34, 2017.

. Discursos sobre a primeira década de Tito Lívio. Trad. MF. São Paulo: Martins Fontes, 2007.

MERLEAU-PONTY, Maurice. Signes. Paris: Les Éditions Gallimard, 1960.

SKINNER, Quentin. Fundações do Pensamento Político Moderno. Trad. Renato Janine Ribeiro e Laura Teixeira Motta. São Paulo: Cia. Das Letras, 1996.

VALENTE, M. A Ética Estóica em Cícero. Caxias do Sul: EDUCS, 1984.

Endereço do Autor:

Rua Girassol, 488, Apto. 151

Vila Madalena

05433-001 São Paulo - SP

sercard@usp.br 